\title{
Consumers Beware: Online Personalized Pricing in Action! How the Framing of a Mandated Discriminatory Pricing Disclosure Influences Intention to Purchase
}

\author{
Willem H. van Boom ${ }^{1}$. Jean-Pierre I. van der Rest ${ }^{2}$ (D) Kees van den Bos ${ }^{3}$. \\ Mark Dechesne ${ }^{4}$
}

Published online: 3 February 2020

(c) The Author(s) 2020

\begin{abstract}
Online businesses collect a wealth of data on customers, often without properly informing them. Increasingly, these data can be used for behavioral price discrimination. In this two-study article, we explore how consumers would respond if businesses were compelled to disclose their use of discriminatory behavioral pricing techniques. Using different disclosure frames, we examine the effects of disclosure on purchase intention and purchase probability. The findings indicate that specific disclosure frames affect purchase intentions. Furthermore, we find that a disclosure frame that is more in line with a consumer's self-interest increases purchase intention. Specifically, the frame indirectly influences intention to purchase through its effect on the perception that the use of behavioral pricing information serves selfinterest. In this way, our study draws attention to a potentially unanticipated effect of regulatory intervention. Implications for future research and legal policy are discussed, focused on the need to design and empirically test the effectiveness of disclosures online.
\end{abstract}

Keywords Personalized pricing $\cdot$ Behavioral price discrimination $\cdot$ Mandatory disclosure $\cdot$ Warning frames $\cdot$ Information regulation $\cdot$ Privacy

\section{Introduction}

Online traders have a wealth of information on their customers which they may process and use to the advantage of their customers. They can, however, also use it to their own commercial advantage. Indeed, some have argued that traders will exploit any opportunity to take advantage of psychological or informational weakness of consumers, if necessary by use of manipulation and deception (Akerlof \& Shiller,

Jean-Pierre I. van der Rest

j.i.van.der.rest@law.leidenuniv.nl

Extended author information available on the last page of the article 
2015). Currently, with the advent of sophisticated techniques for building customer profiles, opportunities for such practices abound. These techniques allow online businesses to make personalized offers to their customers, both in terms of what is offered and the price of the offer. One of these practices, discriminatory behavioral pricing, involves the use of customer profiling techniques in online businessto-consumer (B2C) commerce to set a personalized reservation price that optimally captures the price a customer is willing to pay and which in reality may be lower or higher than the prices offered to others (Gelbrich, 2011; Kannan \& Kopalle, 2001).

As an effective form of direct (first-degree) price discrimination, personalized behavioral pricing was found to boost a seller's profits at the expense of the consumers (Esteves \& Resende, 2019). Customers are typically unaware of the use of this technique, as is the case with several other (one-to-one) marketing practices (Baker, Dickinson, \& Hollander, 1986; Gelbrich, 2011; Goodwin, 1991; Rust, Kannan, \& Peng, 2002). However, the difference with the more common dynamic pricing practices based on differential factors such as day and time of sale is that behavioral price discrimination enables traders to offer an individualized price to individual customers based on their personal behavioral profile, not on whether the general demand for the item on sale is higher or lower at a given point in time. When informed of dynamic pricing practices, consumers may appreciate that the price they pay is higher because of a surge in demand at particular times of the day (Kahneman, Knetsch, \& Thaler, 1986; Martin, Ponder, \& Lueg, 2009). Yet, they may be less understanding if they discover that the behavioral price they pay for exactly the same product on the exact same date and time is higher than that paid by other consumers for the mere reason that computer algorithms can discretely estimate who is less price sensitive or has more to spend. These consumers may then feel tricked and abused if they became aware of these differentials.

Indeed, the literature on perceived price fairness consistently and convincingly shows that individuals develop negative emotions and distrust toward businesses that engage in discriminatory pricing practices (Xia, Monroe, \& Cox, 2004). Perceived fairness, trust and repurchase decisions of disadvantaged consumers' are negatively affected (Garbarino \& Maxwell, 2010; Grewal, Hardesty, \& Gopalkrishnan, 2004; Haws \& Bearden, 2006), whereas advantaged consumers tend to experience a host of both positive and negative emotions (Gelbrich, 2011). Hence, discriminatory behavioral pricing practices may erode trust in online commerce as a whole (Office of Fair Trading, 2013), and customer privacy in particular (Rust et al., 2002). This erosion could justify regulatory intervention (Zuiderveen Borgesius, 2014).

Currently, in European law there is no rule that requires identical prices to be offered to consumers in online sales apart from the prohibition of discrimination on the basis of, for example, gender. Moreover, there is no specific rule demanding that the use of personal profiles for the purpose of price-setting is disclosed to customers (Rott, 2015). The general goal of the European legal framework for consumer protection is to enable consumers to make so-called informed transactional decisions; it prohibits commercial practices that withhold material information needed by the average consumer to take such decisions and thereby cause or potentially cause the average consumer to take a transactional decision that s/he would not have taken otherwise (art. 7 Unfair Commercial Practices Directive 2005/29/EC). Therefore, if 
there is strong evidence that consumers who are given information on the use of behavioral price discrimination respond substantially differently from those who are not, there may be a case for regulatory intervention at a European level. One important legal issue concerns the question whether we deem it fair and just that online prices may vary depending on seemingly irrelevant criteria without proper notification to customers.

In regulatory terms, the exposure of covert discriminatory behavioral pricing practices, by bringing them explicitly to the attention of the customer when entering the online purchasing process, may address some of the 'failures of privacy selfmanagement' identified in the current consent practice (Solove, 2013). As observed by (Acquisti, Brandimarte, \& Loewenstein, 2015), while privacy concerns are not always at the forefront of consumers' minds, when prompted they do display concerns about their privacy and they act accordingly. However, previous work on information regulation also shows that informing individuals ex-ante that they are about to be 'defaulted' or 'nudged' does not necessarily alter the impact of defaults, nor does informing them ex-post (Loewenstein, Bryce, Hagmann, \& Rajpal, 2015). So, whether information regulation can influence market behavior when consumers are discriminated through the online customization of prices is still a much-debated issue. What is clear, however, is that with the spread of big data in marketing, the issue whether regulatory intervention is warranted is likely to become increasingly urgent (Seizov, Wulf, \& Luzak, 2019). One of the obvious regulatory options would then be to introduce some form of mandatory disclosure to consumers. The rationale for mandated behavioral price discrimination disclosure would be that it empowers consumers to act on the information given, to decide whether they feel comfortable with such practices and to shop elsewhere if they do not. The question then arises as to what would be the actual effect of a disclosure statement? And, more in particular, would that effect depend on how the statement is framed? It is these two questions that we explore in this article.

In this article, we investigate how the framing of disclosure messages influences consumer attitudes and purchase intentions in an online shopping context. This is important from a practical point of view as regulatory interventions in online sale processes tend to depart from the neoclassic economic information paradigm. In Europe at least, information regulation seldom takes form, timing, framing and phrasing of the disclosure into account. Instead, disclosure duties tend to be formulated in open-textured phrases which leave ample leeway to businesses to use the frame which is best aligned with their commercial interest. Also, to our knowledge, no research has been conducted on whether the frame of a disclosure statement impacts the intended effect of the intervention. So, we seek to apply behavioral regulation insights in a mainstream information economics setting. In doing so, we explore the disclosure effect on purchase intention in a multi-attribute compositional trade-off context.

From random utility theory (Ben-Akiva \& Lerman, 1985; McFadden, 1974), it can be derived that purchase intentions are based on additive utility. This implies that purchase intentions are not derived from a product per se, but from the different characteristics a product possesses (Lancaster, 1966; Vodopivec, 1992). As a consequence, purchase intention is driven by trading off multiple product attributes. By 
applying these insights in a setting involving disclosure statements, the empirical challenge of the study is to systematically manipulate multiple independent factors (i.e., product attributes) to elicit preferences for combinations of attribute (level)s. To achieve this, we use conjoint analysis, a stated preference elicitation method that is widely accepted in the marketing research community (Green, Krieger, \& Wind, 2001), in which a range of fractional factorial arrays are applied to measure intention to purchase.

\section{Framing of Disclosures}

Markets are complex environments for consumers. Both informational 'noise,' which causes obfuscation and overload, and classic information asymmetries challenge consumers to compare offerings. Indeed, economic theory posits that where market actors fail to disclose essential information, the resulting asymmetries cause market failure (Radner, 1968). Mazis, Staelin, Beales and Salop (1981, p. 12) argue that 'when any informational market failure exists, i.e., when consumer decisions (signals) are based on false or limited information,' information regulation may be appropriate. In this light, a Pareto improving intervention such as a mandated disclosure of information serves to rectify asymmetries, to support informed consent in contract making decisions and to enhance competition (OECD, 2010; Ogus, 2004). European consumer law has thus developed numerous precontractual information duties (OECD, 2010). However, this line of legal thinking does not overly concern itself with how and when such information is filtered, phrased, framed and offered by the information provider, or received, processed and converted into action by the bounded receiver. Meanwhile, under influence of the behavioral sciences (e.g., psychology, marketing), our understanding of information processing by individuals has become more refined (Koehler \& Harvey, 2008; Statt, 1998). Several of these insights are relevant for our purposes.

One of the findings is that in written communication on a particular phenomenon, the effectiveness of the information is dependent on the context in which it is given. That is, information needs to be both comprehensible and specific in terms of the operative mechanism and the exact nature of the phenomenon involved in order to enable the receiver to assess both the content and implications of the message (Wogalter, 1999, 2006). The mere fact that information concerning a particular phenomenon is offered by a provider as well as received, perceived and processed by a receiver does not automatically cause the receiver to change attitudes and adapt behavior. It is the context (e.g., when, how, at what stage) in which the actual message operates that matters, as does the poignancy (i.e., the degree of mental appeal) of the message on the potential (adverse) consequences of the phenomenon (Pape, 2011). That is, varying the poignancy by varying the information disclosure framing can elicit varied behavioral responses in the receiver (i.e., consumer).

Another relevant insight is that while in markets with a discriminatory or personalized pricing regime purchase intentions are impacted by perceptions of price fairness (Darke \& Dahl, 2003; Maxwell \& Garbarino, 2010; Richards, Liaukonyte, \& Streletskaya, 2016; Riquelme, Román, Cuestas, \& Iacobucci, 2019); the literature on 
price framing also shows that when comparing prices consumers tend to 'only base their decisions on the salient characteristics of the situation rather than on the objective price information' (Bayer \& Ke 2013, p. 215). This price-framing effect is supported by previous marketing research, such as Inman, McAlister and Hoyer (1990) who suggest that the promotion signal can be sufficient for consumers to choose the promoted product, independent of the relative price information.

We integrate the studies on information processing, perceived price fairness and price framing. Drawing from procedural justice (e.g., Maxwell, 2002) and social norm theory (e.g., Garbarino \& Maxwell, 2010), we expect that purchase intention is impacted when the rules used to set a personalized price are disclosed, but that this effect is specific to the industry or market (Maxwell \& Garbarino, 2010; Xia et al., 2004) 'as perceptions of justice are made relative to social norms that have evolved differently from one context to the next' (Richards et al., 2016, p.140). Furthermore, combining the notions of 'self-interested inequity aversion' (Liaukonyte, Richards, Kaiser, \& Rickard 2015; Richards et al., 2016) and salience in price framing (Bayer $\& \mathrm{Ke}, 2013)$, we also expect that this disclosure effect is asymmetric and situational. That is, in a market where consumers are used to paying different prices (Garbarino \& Maxwell, 2010), an information disclosure that indicates the procedure used to personalize prices-regardless of the clarity and concreteness of its frame, will impact intention to purchase if it is perceived to be in line with self-interest.

Thus, to examine this information disclosure framing effect, we conducted an experimental study wherein we exposed participants in an online hotel booking experience context to a disclosure message in which the salience of the self-interest was varied through a clear and concrete indication of the behavioral pricing mechanism in operation, or a more ambiguous indication of the behavioral mechanisms used.

Having described the rationale for examining disclosure framing effects, we now will introduce the design of our study and the research methods that we used. After we have discussed the results from our main experiment, we also discuss our 'Post Hoc experiment,' in which we addressed the replicability of the main study. After having presented both experiments, we discuss our findings, the associated theoretical and policy implications, as well as limitations and directions for future research.

\section{Methods}

\section{Experimental Design}

Our design consisted of five between-subjects conditions. Four different experimental groups were exposed to a disclosure statement. The fifth condition was a control group condition that was not exposed to a disclosure statement. To vary the salience of the self-interest, two unambiguous and two ambiguous frames were chosen. In line with 'self-interested inequity aversion' research, one unambiguous inadvantageous (i.e., the price paid is 'higher' than others) and one unambiguous advantageous (i.e., a 'lower' price than others) frame was formulated. As the two equitable (i.e., neutral) but ambiguous disclosure frames, one 'higher/lower' and one 
'appropriate' information disclosure was developed. Table 1 shows the disclosure messages that were presented to participants in the experimental groups:

In European law, information disclosure duties tend to be formulated in opentextured phrases. For instance, certain information is to be given in a 'clear and prominent' or 'comprehensible manner' (art. 5 and 8 Consumer Rights Directive 2011/83/EC) or may not be given 'in an unclear, unintelligible, ambiguous or untimely manner' (art. 7 Unfair Commercial Practices Directive 2005/29/EC). Such broadly phrased standards leave businesses ample leeway to use the frame which is best aligned with their commercial interests, and, therefore, there is every reason to test more specified forms of disclosure wordings. This is exactly what we aimed for with the frames chosen for the experiment.

\section{Sample Characteristics}

Data were collected through an online questionnaire, and the responses were recorded using Sawtooth survey software. The participants were students from a large Dutch university; a student sample was preferred to ensure response homogeneity (Peterson, 2001). A total of 426 students participated. Over a period of 6 weeks, students were randomly invited to participate at different moments of the day in different locations by four trained research assistants carrying iPads on which they presented the information. Students were also invited to participate by e-mail; they then participated in the experiment via their computer (way of sampling did not affect the results obtained). The sample included 152 men (35.7\%) and 274 women $(64.3 \%)$, with an average age of 21.9 years $(\mathrm{SD}=2.9)$. There was no significant difference in gender $\left[\chi^{2}(4)=3.391, p=.495, \Phi=.089\right]$ and age $[F(4,422)=0.624$, $\left.p=.646, \eta^{2}=.006\right]$ between the five groups. Participants were randomly assigned to the groups by a randomizer in the software.

\section{Procedures and Measures}

The questionnaire was divided into three parts. The first part included two scaleseach rated on a Likert scale from one (strongly disagree) to seven (strongly

Table 1 Overview of disclosure frames per experimental group

\begin{tabular}{ll}
\hline Label & Disclosure message \\
\hline Higher & $\begin{array}{c}\text { Our website determines the price you are offered on the basis of your previous purchasing } \\
\text { behavior. Your price is therefore higher than the price offered to others }\end{array}$ \\
Higher/lower & $\begin{array}{l}\text { Our website determines the price you are offered on the basis of your previous purchasing } \\
\text { behavior. Your price is therefore higher or lower than the price offered to others }\end{array}$ \\
Appropriate & $\begin{array}{c}\text { Our website uses your buying habits to make you offers and to offer you an appropriate } \\
\text { price }\end{array}$ \\
Lower & $\begin{array}{l}\text { Our website determines the price you are offered on the basis of your previous purchasing } \\
\text { behavior. Your price is therefore lower than the price offered to others }\end{array}$
\end{tabular}

Upmost care was given to the translation of the disclosure messages in this article. The original texts were in Dutch, the native language of the participants 
agree) — to measure attitude toward trust (Cronbach's $\alpha=0.73$ ) and loyalty (Cronbach's $\alpha=0.83$ ). Trust was measured using five items (Yamagishi \& Yamagishi, 1994): 'Most people are honest,' 'Most people are trustworthy,' 'Most people are good and kind,' 'Most people are trustful of the intentions of others,' 'I am trustful.' Loyalty included: 'If I choose a certain product, I will remain loyal to the brand,' 'I find it important to stay true to brands or products,' 'I find it difficult to buy a product from another brand once I have the choice made for a specific brand,' 'I strongly identify myself with the products that I purchase,' 'I find it important to remain faithful to brands or products.' Trust and loyalty are reported in the literature as predictors of purchase intention (Bonsón Ponte, Carvajal-Trujillo, \& Escobar-Rodríguez, 2015; McCole, Ramsey, \& Williams, 2010). They were measured to verify that the control and experimental groups did not differ in levels of trust and loyalty. Utilizing choice-based conjoint (CBC) analysis methodology, the second part comprised $12 \mathrm{CBC}$ tasks, of which 11 random tasks (in which three hotel concepts were randomly varied per participant per task) served to estimate the individual attribute level part-worths/utilities of the participants, and one fixed (holdout) task was used (in which three fixed hotel concepts were equal for all participants; placed between random tasks four and five) to measure the intention to purchase (on a Likert scale) as well as the probability to purchase (derived from the total individual utility per fixed hotel concept of each participant). Before starting with the CBC tasks, all participants received the same instruction: to make an online hotel reservation for a local festivity well known to the participants. In addition, the experimental groups (not the control group) received a disclosure message (condition). The execution of each CBC task involved answering the following question: 'If you were considering booking the hotel, which would you choose?' For task complexity, level overlap, and design efficiency purposes, three concepts (i.e., options) were given per (random/fixed) choice task. Each concept represented a hotel choice involving the four most preferred hotel attributes: star category, review rating, distance to city center and price (Kim, Kim, King, \& Heo, 2019). Table 2 provides an illustration of such choice task, the fixed (holdout) task, with a luxury (highest attribute levels), midrange (middle attribute levels) and economy (lowest attribute levels) concept (i.e., hotel options one, two, and three).

When stating the preferred choice in the fixed (equal for all) $\mathrm{CBC}$ task, participants were asked to indicate intention to purchase and perceived price fairness on a scale from one (strongly disagree) to seven (strongly agree). The third part of the

Table 2 Fixed choice-based conjoint choice task
If you were considering booking the hotel, which would you choose?

\begin{tabular}{llll}
\hline Star category & 4-star & 2-star & 3-star \\
Review rating & Fantastic: 9+ & Acceptable: 6+ & Very good: 8+ \\
Distance to center & $0.1 \mathrm{~km}$ & $3.3 \mathrm{~km}$ & $1.7 \mathrm{~km}$ \\
Price & $€ 111.80$ & $€ 63.20$ & $€ 89.90$ \\
& 0 & $\bigcirc$ & $\bigcirc$ \\
\hline
\end{tabular}


questionnaire included a brief survey on the socio-demographics gender and age, as well as a question to check if the participants remembered the condition. As a final question for each of the disclosure messages, participants were asked whether they considered it fair if a booking site utilized the discriminatory behavioral pricing policy.

To explore the effects of information disclosure on purchase intention in light of all possible combinations of hotel attribute levels (i.e., not only those attribute combinations that were shown in the three concepts of the fixed task), the eleven random CBC tasks were thus added to create an additional indirect measure of intention to purchase. It should be noted that there are two viewpoints on how to design CBC studies: (1) fixed orthogonal designs (i.e., a single version of the choice tasks is shown to all participants, or subsets of tasks are shown to different groups of participants); and (2) controlled random designs (i.e., each participant receives a unique set of choice tasks). We chose the latter since it reduces biases (compared to fixed designs) resulting from order and learning effects. Also, random designs are more robust in the estimation of all possible trade-offs. Importantly, with a fixed design we would have been able to measure individual part-worths on a much smaller fraction (i.e., 12/167 $=7.19 \%$ ) of all 500 possible attribute trade-offs (i.e., 5 levels [star category] $\times 4$ levels [review rating] $\times 5$ levels [distance to city center] $\times 5$ levels [price] $=5 \times 4 \times 5 \times 5=500$ attribute trade-off combinations). Given that we presented three concepts per task, a full profile full-factorial fixed design would have resulted in a questionnaire with $500 / 3=167$ tasks.

Complete enumeration (i.e., all possible [500] concepts) was chosen as randomization design strategy. The random selection of (subsets of) all possible combinations of the four attributes per concept/option per task thereby conformed to the following design principles: minimal overlap (attribute levels were repeated as few times as possible within a single task), level balance (each attribute level was shown as equally often as possible) and orthogonality (all pairings of attribute levels shown were balanced and uncorrelated). Using the default setting of the specialist CBC software (Sawtooth SSI Web 8.3.8), 300 unique sets of 11 random CBC tasks were generated. Participants were randomly assigned to each of the 300 task sets.

The individual part-worth (attribute level) utilities were estimated with a Hierarchical Bayesian Monte Carlo Markov Chain algorithm (Sawtooth CBC/HB 5.5.3). As participants could not all be drawn from a single multivariate-normal distribution, given the four different experimental conditions, group membership was included as a covariate in the Hierarchical Bayes (HB) run. With the estimated utilities per attribute level per participant, an additive utility model (Fishbein, 1963) was used to determine the utility each participant assigned to each of the three hotel concepts in the fixed ("holdout") task:

$$
U_{p i}=\sum_{k=1}^{K} B_{k} X_{k i},
$$

where $X_{k i}=$ dummy variable indicates the presence of an attribute level $k$ from a set of $K$ attribute levels in fixed hotel concept $i$. $B_{k}=$ the marginal utility associated with attribute level $k$. 
The total utility per fixed hotel concept per individual then served as input for a multinomial logit (MNL) model for each participant:

$$
\operatorname{Pr}\left(Y_{p}=i\right)=\frac{\exp \left(U_{p i}\right)}{\exp \left(U_{p h}\right)+\exp \left(U_{p i}\right)+\exp \left(U_{p j}\right)},
$$

where $\operatorname{Pr}\left(Y_{p}=i\right)=$ the probability that participant $\mathrm{p}$ will choose $i$ from a set. $U_{p h}=$ utility that participant $p$ associates with fixed hotel alternative (concept) $h$. $U_{p i}=$ utility that participant $p$ associates with fixed hotel alternative (concept) $i$. $U_{p j}=$ utility that participant $p$ associates with fixed hotel alternative (concept) $j$.

Using this model, we determined the probability that a participant would purchase a hotel concept in the fixed (equal to all) CBC task. Probability to purchase thus served as a second dependent variable, an additional indirect multi-attributelevel based measure, to explore the effect of the disclosure frame on intention to purchase, and to enhance the robustness of the findings.

\section{Data and Descriptive Analyses}

\section{Descriptive Statistics}

Table 3 shows the mean (and SD) values per measure per condition. For each condition, the intention to purchase (on a Likert scale: 1-7) is provided. Moreover, the probability to purchase is given for each of the three options (in percentages: summing up to $100 \%$ ). With regard to the percentage weight of each attribute in the total preference for a hotel choice, price is the most important attribute in the high $(M=27.86 \%)$ and high/low $(M=28.43 \%)$ conditions, compared to the other conditions, but the difference is insignificant $\left[F(4,404)=1.568, p=.182, \eta^{2}=.015\right]$.

As Table 3 shows, participants disagreed $\left(M_{409}=2.03\right)$ that, in general, most people are trustworthy. Participants also scored low on loyalty $\left(M_{409}=2.00\right)$. Overall, participants did not feel treated fairly when a booking site offered a pricing policy in which personal buying habits were used to calculate individualized prices. Participants felt treated least fairly when personalized prices were higher $(M=1.74)$, followed by higher/lower $(M=2.33)$, lower $(M=3.12)$, and appropriate $(M=3.69)$. Between conditions, significant effects were observed on 'higher/lower' pricing policy $[F(4$, $\left.393)=3.234, p=.013, \eta^{2}=.032\right]$ and 'lower' policy $[F(4,393)=3.109, p=.015$, $\left.\eta^{2}=.031\right]$, indicating that these policies were not considered equally fair in all five conditions. In addition, no significant effects were found regarding the perceived price fairness of the chosen (fixed) hotel option $\left[F(4,404)=1.363, p=.246, \eta^{2}=.013\right]$.

\section{Utility Estimates}

Prior to using the questionnaire, the CBC design was tested for ordinary leastsquares (OLS) efficiency (Kuhfeld, Tobias, \& Garratt, 1994). When compared with a precise orthogonal design the randomized design had a median efficiency of $99.98 \%$. 


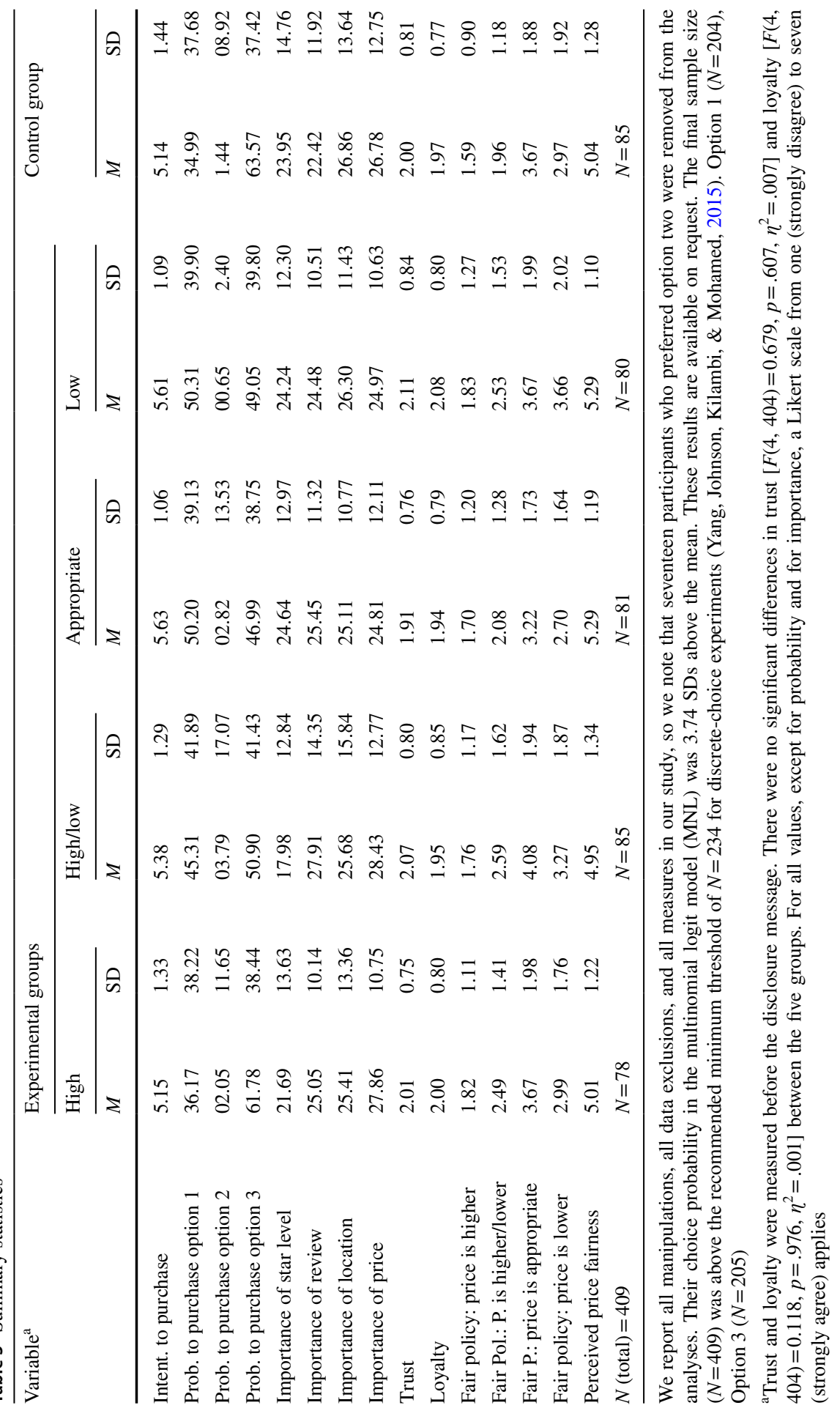


Standard errors remained within limits of less than 0.025 (for main effects) and 0.05 (for interaction effects), indicating that the simulated data met the minimum sample size and had an acceptable level of precision. To estimate utilities, 150,000 iterations were completed resulting in an acceptable root likelihood goodness of fit $\left(\mathrm{RLH}_{\mathrm{m}}=0.8255\right)$. Table 4 shows that all utility values were significant $(p<.001)$. As can be observed, all higher attribute levels have higher utilities (i.e., preference), with the exception of price (i.e., a reversed preference).

\section{Results}

\section{Manipulation Check}

At the end of the experiment, participants were asked to recall which pricing policy (none, higher, higher/lower, appropriate, lower) the booking site utilized. The levels

Table 4 Summary statistics of utility estimates

\begin{tabular}{|c|c|c|c|c|}
\hline \multirow[t]{2}{*}{ Attribute $^{\mathrm{a}}$} & \multirow[t]{2}{*}{ Level } & \multicolumn{3}{|l|}{ Utility } \\
\hline & & Mean & SD & SE \\
\hline \multirow[t]{4}{*}{ Star category } & 5-star hotel & $6.482 * * *$ & 4.812 & .233 \\
\hline & 4-star hotel & $5.839 * * *$ & 4.229 & .204 \\
\hline & 3-star hotel & $4.722 * * *$ & 3.324 & .161 \\
\hline & 2-star hotel & $2.658 * * *$ & 2.062 & .099 \\
\hline \multirow[t]{3}{*}{ Review rating } & Fantastic: $9+$ & $7.654 * * *$ & 4.088 & .198 \\
\hline & Very good: $8+$ & $6.911 * * *$ & 3.704 & .179 \\
\hline & Good: $7+$ & $4.572 * * *$ & 2.760 & .133 \\
\hline \multirow[t]{4}{*}{ Distance to city center } & $0.1 \mathrm{~km}$ & $7.702 * * *$ & 4.279 & .207 \\
\hline & $0.9 \mathrm{~km}$ & $6.800 * * *$ & 3.737 & .181 \\
\hline & $1.7 \mathrm{~km}$ & $4.722 * * *$ & 2.783 & .134 \\
\hline & $2.5 \mathrm{~km}$ & $2.215 * * *$ & 1.241 & .060 \\
\hline \multirow[t]{4}{*}{ Price } & $€ 63.20$ & $8.377 * * *$ & 4.798 & .232 \\
\hline & $€ 76.50$ & $7.319 * * *$ & 4.012 & .194 \\
\hline & $€ 89.90$ & $5.800 * * *$ & 2.945 & .142 \\
\hline & $€ 103.10$ & $2.223 * * *$ & 1.385 & .067 \\
\hline
\end{tabular}

In terms of the interpretation of these values, while it is incorrect to compare two single utility values (e.g., 3-star $[M=4.72]$ does not have the same desirability as $1.7 \mathrm{~km}[M=4.72]$ ), one can conclude that the higher preference for a 3-star hotel, compared to a 2-star $(M=4.72-2.66=2.06)$, is comparable to the higher preference for $0.9 \mathrm{~km}$ distance, compared to $1.7 \mathrm{~km}(M=6.80-4.72=2.07)$. The average participant would thus be more or less indifferent between a 3-star hotel located at $1.7 \mathrm{~km}$ from the center $(M=4.72+4.72=9.44)$ and a 2 -star hotel located at $0.9 \mathrm{~km}$ $(M=2.66+6.80=9.46)$

${ }^{\text {a }}$ Sample means are provided for the full sample $(N=426)$. Lowest attribute level set at 0 (dummy coding), including 1-star hotel***, Okay: $6+* * *, 3.3 \mathrm{~km}^{* * *}$ and $€ 111.80 * * *$. ***p $<.001$ 
of successful recall were $75.0 \%$ (control), $84.6 \%$ (higher), $80.0 \%$ (higher/lower), $88.8 \%$ (appropriate) and $83.8 \%$ (lower). Analysis of the odds ratios using logistic regression indicated no significant difference $\left[R_{\text {Nagelkerke }}^{2}=.017, \chi^{2}(4)=4.42, p=.35\right]$ in recalling the correct pricing policy between the five groups.

\section{Purchase Intentions}

To explore whether behavioral pricing disclosure influenced purchase intentions, a one-way analysis of variance (ANOVA) was conducted with five levels (no disclosure message, higher, higher/lower, appropriate, lower), and with intention to purchase as dependent variable. This yielded a significant effect on purchase intentions $\left[F(4,404)=2.90, p=.022, \eta^{2}=.028\right]$. To test for robustness, the analysis was repeated on probability to purchase (i.e., the second dependent variable), for the luxury hotel concept (option one) $\left[F(4,404)=2.88, p=.022, \eta^{2}=.028\right]$ and the midrange concept (option three) $\left[F(4,404)=3.12, p=.015, \eta^{2}=.030\right]$, all of which supported the effect (N.B. as only seventeen participants-over five groups-chose the economy hotel concept (option two), they were excluded from the analysis). In other words, the specific information disclosure frame was shown to affect intention to purchase. Means relevant for these analyses are given in Table 3.

To further explore the nature of the framing effect, we conducted a planned comparison of the control condition (in which no behavioral pricing policy was disclosed) with the four experimental conditions. Because Levene's test of homogeneity was significant $(p<.05)$, Hartley's $F_{\max }$ test was performed, which satisfied the homogeneity of variance assumption $(1.81<2.04)$. Planned contrasts revealed that having a behavioral pricing disclosure frame significantly affected both intention to purchase $t(404)=1.97, p=.049, r_{\mathrm{c}}=0.10, d=0.20$, and probability to purchase $t(404)=2.18, p=.029, r_{\mathrm{c}}=0.11, d=0.22$ (option one) and $t(404)=2.38, p=.018$, $r_{\mathrm{c}}=0.12, d=0.24$ (option three). This indicates that, overall, the intention to purchase tended to be higher in the conditions where behavioral pricing information was provided when compared to the conditions where it was not. Post hoc comparisons (least significant difference tests) were performed which revealed that the mean levels of intention to purchase in the control and higher conditions were significantly different from the appropriate and lower conditions.

Polynomial trend analyses yielded a more exact understanding of the nature of this effect. In order to make these trend analyses meaningful, we ordered the conditions along an assumed continuum of self-interest. The condition where participants paid a higher price was considered the least in line with self-interest, then the higher/ lower condition, followed by the appropriate condition, while the lower price was considered to be of greatest self-interest. Particularly noteworthy was a significant linear trend at $F(1,404)=10.48, p<.001, \eta^{2}=.159$, indicating that the content of the information disclosure most affected intention to purchase rather than the information frame itself. In particular, as the behavioral pricing information was more in line with self-interest, the intention to purchase increased. This interpretation was further corroborated by the findings that neither quadratic $[F(1,404)=.003, p=.955$, 
$\left.\eta^{2}=.003\right]$ nor cubic $\left[F(1,404)=1.17, p=.279, \eta^{2}=.053\right]$ trends yielded significant results, showing that trends deviating from the linear self-interest explanation had less predictive power.

\section{Post Hoc Experiment}

The study was repeated post hoc to test the self-interest effect, as well as to assess the replicability of the experiment under non-EU participants. Two changes were made to the design. First, those participants who were shown a disclosure message were also asked to state whether the use of information about their purchasing behavior (i.e., the behavioral pricing policy) served their self-interest: 'When using the information about my buying behavior, my interest is served.' Second, for an improved understanding of the 'appropriate' condition, a comparison frame was included: 'the price you pay is the same price as offered to others' (i.e., 'same').

US Participants $(n=186)$ were recruited through MTurk and received $\$ 1.00$ for completing the questionnaire. Evidence shows that collecting crowdsourced data via platforms such as MTurk is highly reliable (Buhrmester, Kwang, \& Gosling, 2011; Paolacci \& Chandler, 2014; Paolacci, Chandler, \& Ipeirotis, 2010). Moreover, MTurk samples are found to be representative for the US population and strong in external validity (Huff \& Tingley, 2015). Comparing participants to original samples and replication samples, Firth, Hoffman and Wilkinson-Ryan (2017) also state that MTurk samples are highly reliable and useful in experimental legal studies. The participants were American citizens with an average age of 22.7 years $(\mathrm{SD}=1.8)$. The sample included eighty-nine men $(47.8 \%)$ and ninety-seven women (52.2\%). Among participants, $102(54.8 \%)$ studied and eighty-four (45.2\%) did not study at college or university level. There was no significant difference in gender $\left[\chi^{2}(1)=0.124, p=.725, \Phi=.204\right]$ between students and non-students. A small but significant age difference $\left[F(1,185)=17.796, p<.001, \eta^{2}=.088\right]$ was found between those who studied $(M=22.2, \mathrm{SD}=1.9)$ and those who did not $(M=23.3$, $\mathrm{SD}=1.7)$. In addition, there was no significant difference in gender $\left[\chi^{2}(5)=7.713\right.$, $p=.173, \Phi=.204]$ or age $\left[F(5,185)=1.196, p=.313, \eta^{2}=.032\right]$ between the six conditions.

The results of this second study (see Table 5) show that the order of the conditions along the assumed continuum of self-interest (first experimental study) was confirmed by the ascending mean values of the perception that the use of information about purchasing behavior served self-interest, $F(1,149)=51.63, p<.001$, $\eta^{2}=.263$, as was intention to purchase, $F(1,182)=8.27, p<.01, \eta^{2}=.063$. Moreover, the (adjusted) mean intentions to purchase of the 'appropriate' and 'same' frames were similar, with a slightly higher (0.15) mean self-interest for 'same,' indicating that 'appropriate' had a similar effect as 'same.' Following Hayes and Preacher (2014) and Hayes (2018), performing mediation analysis with a multicategorical independent variable using OLS path analysis, the disclosure frame was found to indirectly affect intention to purchase through its effect on the perception that the use of behavioral pricing information served self-interest. The levels 
Table 5 Summary statistics for self-interest serving post hoc experiment

\begin{tabular}{|c|c|c|c|c|c|}
\hline & & & $\begin{array}{l}Y \\
\text { Intention to } \\
\text { purchase }\end{array}$ & $\begin{array}{l}M \\
\text { Self-interest }\end{array}$ & $\begin{array}{l}\bar{Y} \\
\text { Adjusted }\end{array}$ \\
\hline Control & $N=34$ & $\begin{array}{l}\text { Mean } \\
\text { SD }\end{array}$ & $\begin{array}{l}5.44 \\
1.05\end{array}$ & & \\
\hline Higher & $N=32$ & $\begin{array}{l}\text { Mean } \\
\text { SD }\end{array}$ & $\begin{array}{l}5.47 \\
0.80\end{array}$ & $\begin{array}{l}2.94 \\
1.81\end{array}$ & 5.59 \\
\hline Higher/lower & $N=36$ & $\begin{array}{l}\text { Mean } \\
\text { SD }\end{array}$ & $\begin{array}{l}5.31 \\
0.95\end{array}$ & $\begin{array}{l}3.78 \\
1.71\end{array}$ & 5.35 \\
\hline Appropriate & $N=25$ & $\begin{array}{l}\text { Mean } \\
\text { SD }\end{array}$ & $\begin{array}{l}5.68 \\
0.80\end{array}$ & $\begin{array}{l}4.64 \\
1.96\end{array}$ & 5.65 \\
\hline Same & $N=31$ & $\begin{array}{l}\text { Mean } \\
\text { SD }\end{array}$ & $\begin{array}{l}5.68 \\
0.70\end{array}$ & $\begin{array}{l}4.81 \\
1.35\end{array}$ & 5.63 \\
\hline Lower & $N=30$ & $\begin{array}{l}\text { Mean } \\
\text { SD } \\
\text { Mean } \\
\text { SD }\end{array}$ & $\begin{array}{l}5.97 \\
0.67 \\
5.57 \\
0.87\end{array}$ & $\begin{array}{l}5.63 \\
0.68 \\
4.31 \\
1.82\end{array}$ & 5.85 \\
\hline
\end{tabular}

Total sample mean of intention to purchase $(N=188) . \bar{Y}=$ adjusted mean, adjusted to the sample mean of self-interest (i.e., to reflect the expected difference between the means of the conditions on $Y$ if they were equal on the mediator on average)

We report all manipulations, all data exclusions and all measures in our study. Following Hayes and Preacher (2014), it was verified that a sample size $>20$ was sufficient for the mediation analysis with $X$ as a multicategorical variable

of successful recalling, which were $74.2 \%$ (higher), $61.8 \%$ (higher/lower), $79.2 \%$ (appropriate), $73.3 \%$ (same), $93.1 \%$ (lower), did not substantially change the conclusion of the mediation analysis.

Figure 1 and Table 6 illustrate that participants presented with the higher/lower disclosure message believed that this behavioral pricing policy was more in line with self-interest than those presented with the higher disclosure message $\left(a_{1}=0.840\right)$. A similar effect was found for participants who were presented with the appropriate, the same, or the lower disclosure message $\left(a_{2}=1.703, a_{3}=1.869, a_{4}=2.696\right)$. Moreover, participants who believed that the behavioral pricing policy was more in line with self-interest expressed a stronger intention to purchase $(b=0.089)$. A bias-corrected bootstrap confidence interval (CI) for the indirect effect $\left(a_{1} b=0.075\right.$, $a_{2} b=0.151, a_{3} b=0.166, a_{4} b=0.240$ ), based on 10,000 bootstrap samples, was entirely above zero, with the exception of the higher/lower condition $(-0.000$ to 0.241). There was no evidence that information disclosures affected intention to purchase independent of their effect on the perception that the use of behavioral pricing information was in line with self-interest $(p<.05)$. 


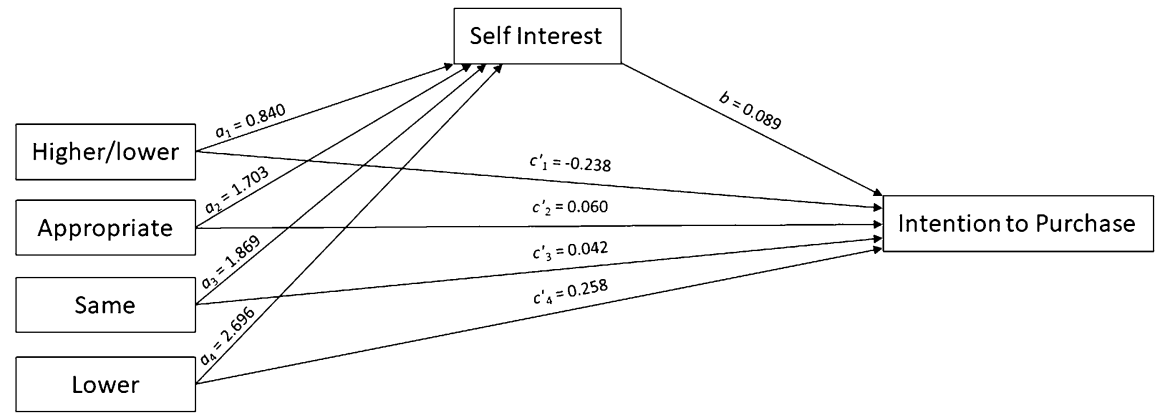

Fig. 1 Estimated model coefficients for disclosure condition

Table 6 Model coefficients for the self-interest serving post hoc experiment

\begin{tabular}{|c|c|c|c|c|c|c|}
\hline \multirow[t]{2}{*}{$X$ (frame) } & \multicolumn{2}{|c|}{$M$ (self-interest) } & \multicolumn{4}{|c|}{$Y$ (intention to purchase) } \\
\hline & & $\begin{array}{l}\text { Coefficient } \\
\text { (SE) }\end{array}$ & & $\begin{array}{l}\text { Coefficient } \\
\text { (SE) }\end{array}$ & & $\begin{array}{l}\text { Coefficient } \\
\text { (SE) }\end{array}$ \\
\hline $\begin{array}{l}\text { Constant } \\
\text { (higher) }\end{array}$ & $i_{1}$ & $\begin{array}{l}2.938 * * * \\
(0.326)\end{array}$ & $i_{3}$ & $\begin{array}{l}5.469 * * * \\
(0.144)\end{array}$ & $i_{2}$ & $\begin{array}{l}5.208 * * * \\
(0.191)\end{array}$ \\
\hline Higher/lower & $a_{1}$ & $\begin{array}{l}0.840^{\mathrm{a}} \\
(0.435)\end{array}$ & $c_{1}$ & $\begin{array}{l}-0.163 \\
(0.216)\end{array}$ & $c_{1}^{\prime}$ & $\begin{array}{l}-0.238 \\
(0.210)\end{array}$ \\
\hline Appropriate & $a_{2}$ & $\begin{array}{l}1.703 * * \\
(0.515)\end{array}$ & $c_{2}$ & $\begin{array}{l}0.211 \\
(0.218)\end{array}$ & $c_{2}^{\prime}$ & $\begin{array}{l}0.060 \\
(0.222)\end{array}$ \\
\hline Same & $a_{3}$ & $\begin{array}{l}1.869 * * * \\
(0.409)\end{array}$ & $c_{3}$ & $\begin{array}{l}0.208 \\
(0.193)\end{array}$ & $c_{3}^{\prime}$ & $\begin{array}{l}0.043 \\
(0.208)\end{array}$ \\
\hline Lower & $a_{4}$ & $\begin{array}{l}2.696 * * * \\
(0.365)\end{array}$ & $c_{4}$ & $\begin{array}{l}0.498 * * \\
(0.190)\end{array}$ & $c_{4}^{\prime}$ & $\begin{array}{l}0.258 \\
(0.227)\end{array}$ \\
\hline \multirow[t]{2}{*}{$\begin{array}{l}M \text { (Self- } \\
\text { interest) }\end{array}$} & & - & & - & $b$ & $\begin{array}{l}0.089 * \mathrm{~b} \\
(0.042)\end{array}$ \\
\hline & \multicolumn{2}{|c|}{$\begin{array}{l}R^{2}=0.263 \\
F(4,149)=17.70, p<.001\end{array}$} & \multicolumn{2}{|c|}{$\begin{array}{l}R^{2}=0.078 \\
F(4,149)=3.188, p=.015\end{array}$} & \multicolumn{2}{|c|}{$\begin{array}{l}R^{2}=0.107 \\
F(5,148)=4.493 \\
p<.001\end{array}$} \\
\hline
\end{tabular}

Since the control condition $(N=34)$ did not receive a self-interest statement (as there was no disclosure message), it was excluded from the mediation analysis $(N=154)$. The higher condition was chosen as reference category as we are interested in the mediating effect of self-interest. That is, we compare the disclosure that is least in line with self-interest (akin the findings of study one) with the other disclosures (in consecutive order of self-interest), thereby showing that framing influences purchasing intention, in particular the extent to which the information hints toward self-interest in purchasing

${ }^{\mathrm{a}} p=.0554$

${ }^{\mathrm{b}} p=.0352$

$* p<.05, * * p<.01, * * * p<.001$ 


\section{Discussion and Implications}

\section{Implications for Theory}

Our results contribute to several areas of research. First, while behavioral pricing research has shown that businesses can mitigate the negative perceptions of behavioral price discrimination through price framing (Weisstein, Monroe, \& Kukar-Kinney, 2013), this study is first to identify that a behavioral pricing disclosure frame can influence intention to purchase. Akin to studies on adverse effects of mandated financial information disclosure (Greenstone, Oyer, \& Vissing-Jorgensen, 2006), and, more general, the unintended consequences of regulation (Peltzman, 1975; Ribstein, 2002; Sunstein, 1990), our findings indicate that unanticipated framing effects of disclosure statements can occur. We show that a frame, which is relatively more in line with self-interest, may in fact increase intention to purchase. That is, it is the phrasing and framing of disclosure message itself that affects the degree to which the use of information about buying behavior is perceived to serve selfinterest, which in turn affects purchase intention. In this way, our findings confirm work on salience: when consumers read that an 'appropriate price' is offered, they do not seem to consider that 'appropriate' may also mean that they are being overcharged. Indeed, they seem to think that they are charged less. And, even when they are offered the 'same' price as others, they may still think that this is not for 'all others,' or that they are still better off than a subjective and internally driven reference price, indicating that a self-serving bias is at work.

Our findings indicate that by drawing attention to a discriminatory behavioral pricing mechanism (through the disclosure), this in itself has an upward effect on intention to purchase. From the literature on reference price research, it can be derived that this upward effect may also relate to purchase quantity, category purchase, purchase-timing and store choice (Mazumdar, Raj, \& Sinha, 2005). If, however, consumers are confronted with a more confusing indication of the potential effect of the behavioral pricing mechanism ('higher/lower than the price offered to others'), the message seems to dampen their enthusiasm and intention to purchase. In this way, we answer to a call by Seizov et al. (2019, p. 149) who criticize the European legislator for disregarding scholarship on effective information design, and who recommend 'empirically tested, interdisciplinary criteria for the design of effective disclosures online, with a focus on their application in the EU,' since 'without clear guidance as to how disclosures should be formulated, traders are left open to accidental or purposeful obfuscation.' If corroborated by further research, the findings of our two studies should heed policymakers to carefully consider the framing and phrasing of mandated disclosure.

Second, a significant effect was found on both the direct measure (i.e., intention to purchase) and the indirect measure (i.e., probability to purchase). The magnitude of this effect was similar (medium) for both intention to purchase and probability to purchase (Cohen's $d=0.20$, resp. $d=0.22$ ). In the context of the dependence of consumer decisions (John, Acquisti, \& Loewenstein, 2011), we thereby contribute to the information regulation literature by providing robust evidence of the framing 
effect. This is an important methodological contribution, as Mattilaand Choi (2014) found distinct differences in consumers' responses to online behavioral discriminatory pricing policy.

\section{Implications for Policy}

In light of concerns about the effectiveness of mandated disclosure (Ben-Shahar \& Schneider, 2014; Mercer, Palmiter, \& Taha, 2010), we believe that the finding that the information disclosure frame increases intention to purchase-particularly the extent to which the information hints toward self-interest in purchasing-is of special interest. It suggests the possibility that framing as a result of regulatory intervention may inadvertently appeal to consumers' wishes, desires, and in the process of doing so, increase the likelihood of (over)spending. Regulatory intervention should at least be partially concerned with raising consumers' resilience to the use of personal information by marketers to stimulate the buying intentions. By disclosing particular information, regulatory interventions may be at risk of playing into the hands of marketers rather than the consumer. The call for regulatory intervention may thus not only imply a regulation of marketing, but may also give rise to an interest in the road-testing of disclosure regulations. As online retailers are increasingly capable of behavioral pricing (Gelbrich, 2011; Kannan \& Kopalle, 2001), there may be a need for a legal psychological approach, sooner than later.

\section{Limitations and Further Research}

We also draw attention to some limitations of our study and directions for research. First, while a student sample-in comparison to a non-student one-may have brought relatively more homogeneity within the measurement scales, it may have also reduced the magnitude of differences among the variables (Peterson, 2001). Thus, we explicitly emphasize the importance of replicating this study with a mixed sample before making further generalizations. Second, the effects of information regulation were measured on the purchase intention of a widely available hospitality service product. The magnitude of behavioral effects may be different for the purchase of for example a technically complex product or for a product with a large financial commitment. Third, as purchase intentions (i.e., stated preferences) do not necessarily lead to actual purchases (i.e., revealed preferences), further experimental research should explore the effect of disclosure frames on actual buying behavior. Fourth, the framing of a different attribute could be manipulated, for example, by disclosing how behavioral data are used for search discrimination purposes (i.e., steering consumers toward different choice sets when they search online within a specific product category). This would allow finding out whether the salience effect of disclosure is robust, or distinct to price.

Acknowledgements Funding was provided by Leiden University's research profile area 'Interaction between Legal Systems (ILS 2.0)'. 
Open Access This article is licensed under a Creative Commons Attribution 4.0 International License, which permits use, sharing, adaptation, distribution and reproduction in any medium or format, as long as you give appropriate credit to the original author(s) and the source, provide a link to the Creative Commons licence, and indicate if changes were made. The images or other third party material in this article are included in the article's Creative Commons licence, unless indicated otherwise in a credit line to the material. If material is not included in the article's Creative Commons licence and your intended use is not permitted by statutory regulation or exceeds the permitted use, you will need to obtain permission directly from the copyright holder. To view a copy of this licence, visit http://creativecommons.org/licen ses/by/4.0/.

\section{References}

Acquisti, A., Brandimarte, L., \& Loewenstein, G. (2015). Privacy and human behavior in the age of information. Science, 347(6221), 509-514.

Akerlof, G. A., \& Shiller, R. J. (2015). Phishing for phools. Woodstock: Princeton University Press.

Baker, R. C., Dickinson, R., \& Hollander, S. (1986). Big Brother 1994: Marketing data and the IRS. Journal of Public Policy \& Marketing, 5(1), 227-242.

Bayer, R.-C., \& Ke, C. (2013). Discounts and consumer search behavior: The role of framing. Journal of Economic Psychology, 39(December), 215-224.

Ben-Akiva, M., \& Lerman, S. (1985). Discrete choice analysis. Cambridge: MIT Press.

Ben-Shahar, O., \& Schneider, C. E. (2014). More than you wanted to know-The failure of mandated disclosure. Princeton, Oxford: Princeton University Press.

Bonsón Ponte, E., Carvajal-Trujillo, E., \& Escobar-Rodríguez, T. (2015). Influence of trust and perceived value on the intention to purchase travel online: Integrating the effects of assurance on trust antecedents. Tourism Management, 47(April), 286-302.

Buhrmester, M., Kwang, T., \& Gosling, S. D. (2011). Amazon's mechanical Turk a new source of inexpensive, yet high-quality, data? Perspectives on Psychological Science, 6(1), 3-5.

Darke, P. R., \& Dahl, D. W. (2003). Fairness and discounts: The subjective value of a bargain. Journal of Consumer Psychology, 13(3), 328-338.

Esteves, R.-B., \& Resende, J. (2019). Personalized pricing and advertising: Who are the winners? International Journal of Industrial Organization, 63, 239-282.

Fishbein, M. (1963). An investigation of the relationship between beliefs about an object and the attitude toward that object. Human Relation, 16(3), 233-239.

Garbarino, E., \& Maxwell, S. (2010). Consumer response to norm-breaking pricing events in e-commerce. Journal of Business Research, 63(9-10), 1066-1072.

Gelbrich, K. (2011). I have paid less than you! The emotional and behavioral consequences of advantaged price inequality. Journal of Retailing, 87(2), 207-224.

Goodwin, C. (1991). Privacy: Recognition of a consumer right. Journal of Public Policy \& Marketing, 10(1), 149-166.

Green, P. E., Krieger, A. M., \& Wind, Y. (2001). Thirty years of conjoint analysis: Reflections and prospects. Interfaces, 31(3), S56-S73.

Greenstone, M., Oyer, P., \& Vissing-Jorgensen, A. (2006). Mandated disclosure, stock returns, and the 1964 Securities Acts amendments. The Quarterly Journal of Economics, 121(2), 399-460.

Grewal, D., Hardesty, D. M., \& Iyer, G. R. (2004). The effects of buyer identification and purchase timing on consumers' perceptions of trust, price fairness, and repurchase intentions. Journal of Interactive Marketing, 18(4), 87-100.

Haws, K. L., \& Bearden, W. O. (2006). Dynamic pricing and consumer fairness perceptions. Journal of Consumer Research, 33(3), 304-311.

Hayes, A. F. (2018). Introduction to mediation, moderation, and conditional process analysis: A regression-based approach. New York: The Guildford Press.

Hayes, A. F., \& Preacher, K. J. (2014). Statistical mediation analysis with a multicategorical independent variable. British Journal of Mathematical and Statistical Psychology, 67(3), 451-470.

Hoffman, D. A., \& Wilkinson-Ryan, T. (2017). Law and psychology grows up, goes online, and replicates. Journal of Empirical Legal Studies, 15(2), 320-355. 
Huff, C., \& Tingley, D. (2015). Who are these people? Evaluating the demographic characteristics and political preferences of MTurk survey respondents. Research \& Politics, 2(3), 1-12.

Inman, J. J., McAlister, L., \& Hoyer, W. D. (1990). Promotional signal: Proxy for a price cut? Journal of Consumer Research, 17(1), 74-81.

John, L. K., Acquisti, A., \& Loewenstein, G. (2011). Strangers on a plane: Context-dependent willingness to divulge sensitive information. Journal of Consumer Research, 37(5), 858-873.

Kahneman, D., Knetsch, J. L., \& Thaler, R. (1986). Fairness as a constraint on profit seeking: Entitlements in the market. The American Economic Review, 76(4), 728-741.

Kannan, P. K., \& Kopalle, P. K. (2001). Dynamic pricing on the internet: Importance and implications for consumer behavior. International Journal of Electronic Commerce, 5(3), 63-83.

Kim, B., Kim, S., King, B., \& Heo, C. Y. (2019). Luxurious or economical? An identification of tourists' preferred hotel attributes using best-worst scaling (BWS). Journal of Vacation Marketing, 25(2), 162-175.

Koehler, D. J., \& Harvey, N. (2008). Blackwell handbook of judgment and decision making. Oxford: Blackwell.

Kuhfeld, W. F., Tobias, R. D., \& Mark Garratt, M. (1994). Efficient experimental design with marketing research applications. Journal of Marketing Research, 31(4), 545-557.

Lancaster, K. J. (1966). A new approach to consumer theory. Journal of Political Economy, 74(2), $132-157$.

Liaukonyte, J., Richards, T. J., Kaiser, H. M., \& Rickard, B. J. (2015). Under-contribution to generic advertising due to self-interested inequity aversion. European Review of Agricultural Economics, 42(3), 473-497.

Loewenstein, G., Bryce, C., Hagmann, D., \& Rajpal, S. (2015). Warning: You are about to be nudged. Behavioral Science \& Policy, 1(1), 35-42.

Martin, W. C., Ponder, N., \& Lueg, J. E. (2009). Price fairness perceptions and customer loyalty in a retail context. Journal of Business Research, 62(6), 588-593.

Mattila, A. S., \& Choi, C. (2014). An analysis of consumers' reactions to travel websites' discrimination by computer platform. Cornell Hospitality Quarterly, 55(2), 210-215.

Maxwell, S. (2002). Rule-based price fairness and its effect on willingness to purchase. Journal of Economic Psychology, 23(2), 191-212.

Maxwell, S., \& Garbarino, E. (2010). The identification of social norms of price discriminationon the internet. Journal of Product \& Brand Management, 19(3), 218-224.

Mazis, M. B., Staelin, R., Beales, H., \& Salop, S. (1981). A framework for evaluation consumer information regulation. Journal of Marketing, 45(1), 11-21.

Mazumdar, T., Raj, S. P., \& Sinha, I. (2005). Reference price research: Review and propositions. Journal of Marketing, 69(4), 84-102.

McCole, P., Ramsey, R., \& Williams, J. (2010). Trust considerations on attitudes towards online purchasing: The moderating effect of privacy and security concerns. Journal of Business Research, 63(9/10), 1018-1024.

McFadden, D. (1974). Conditional logit analysis of qualitative choice behavior. In p zarembka (Ed.), Frontiers in econometrics (pp. 105-142). New York: Academic Press.

Mercer, M., Palmiter, A. R., \& Taha, A. E. (2010). Worthless warnings? Testing the effectiveness of disclaimers in mutual fund advertisements. Journal of Empirical Legal Studies, 7(3), 429-459.

OECD. (2010). Consumer policy toolkit. Paris: OECD Publishing.

Office of Fair Trading. (2013). Personalised pricing: Increasing transparency to improve trust (OFT 1489). London: OFT.

Ogus, A. (2004). Comparing regulatory systems: Institutions, processes and legal forms in industrialised countries. In P. Cook, C. Kirkpatrick, M. Minogue, \& D. Parker (Eds.), Leading issues in competition, regulation and development (pp. 146-164). Cheltenham: Edward Elgar.

Paolacci, G., \& Chandler, J. (2014). Inside the turk: Understanding mechanical turk as a participant pool. Current Directions in Psychological Science, 23(3), 184-188.

Paolacci, G., Chandler, J., \& Ipeirotis, P. G. (2010). Running experiments on amazon mechanical turk. Judgment and Decision making, 5(5), 411-419.

Pape, S. B. (2011). Warnings and product liability: Lessons learned from cognitive psychology and ergonomics. Den Haag: Eleven BJU.

Peltzman, S. (1975). The effects of automobile safety regulation. Journal of Political Economy, 83(4), $677-725$. 
Peterson, R. A. (2001). On the use of college students in social science research: Insights from a secondorder meta-analysis. Journal of Consumer Research, 28(3), 450-461.

Radner, R. (1968). Competitive equilibrium under uncertainty. Econometrica, 36(1), 31-58.

Ribstein, L. E. (2002). Market vs. regulatory responses to corporate fraud: A Critique of the SarbanesOxley Act of 2002. Journal of Corporation Law, 28(1), 1-74.

Richards, T. J., Liaukonyte, J., \& Streletskaya, N. A. (2016). Personalized pricing and price fairness. International Journal of Industrial Organization, 44(January), 138-153.

Riquelme, I. P., Román, S., Cuestas, P. J., \& Iacobucci, D. (2019). The dark side of good reputation and loyalty in online retailing: When trust leads to retaliation through price unfairness. Journal of Interactive Marketing, 47(August), 35-52.

Rott, P. (2015). Der "Durchschnittverbraucher": Ein Auslaufmodell angesichts personalisierten Marketings? Verbraucher und Recht, 5, 163-167.

Rust, R. T., Kannan, P. K., \& Peng, N. (2002). The customer economics of internet privacy. Journal of the Academy of Marketing Science, 30(4), 455-464.

Seizov, O., Wulf, A. J., \& Luzak, J. (2019). The transparent trap: A multidisciplinary perspective on the design of transparent online disclosures in the EU. Journal of Consumer Policy, 42(1), 149-173.

Solove, D. J. (2013). Privacy self-management and the consent dilemma. Harvard Law Review, 13(7), 1880-1903.

Statt, D. A. (1998). Understanding the consumer: A psychological approach. London: Macmillan Press.

Sunstein, C. R. (1990). Paradoxes of the regulatory state. University of Chicago Law Review, 57(2), 407-441.

Vodopivec, B. (1992). A need theory perspective on the parallelism of attitude and utility. Journal of Economic Psychology, 13(1), 19-37.

Weisstein, F. L., Monroe, K. B., \& Kukar-Kinney, M. (2013). Effects of price framing on consumers' perceptions of online dynamic pricing practices. Journal of the Academy of Marketing Science, 41(5), 501-514.

Wogalter, M. S. (1999). Warnings and risk communication. London: Taylor \& Francis.

Wogalter, M. S. (2006). Handbook of warnings. Mahwah, NJ: Lawrence Erlbaum Associates, CRC Press.

Xia, L., Monroe, K. B., \& Cox, J. L. (2004). The price is unfair! A conceptual framework of price fairness perceptions. Journal of Marketing, 68(4), 1-15.

Yamagishi, T., \& Yamagishi, M. (1994). Trust and commitment in the United States and Japan. Motivation and Emotion, 18(2), 129-166.

Yang, Y.-C., Johnson, F. R., Kilambi, V., \& Mohamed, A. F. (2015). Sample size and utility-difference precision in discrete-choice experiments: A meta-simulation approach. Journal of Choice Modelling, 16(9), 50-57.

Zuiderveen Borgesius, F. J. (2014). Improving privacy protection in the area of behavioural targeting. The Hague: Kluwer Law International.

Publisher's Note Springer Nature remains neutral with regard to jurisdictional claims in published maps and institutional affiliations. 


\section{Affiliations}

\section{Willem H. van Boom ${ }^{1}$. Jean-Pierre I. van der Rest ${ }^{2} \oplus \cdot$. Kees van den Bos ${ }^{3}$.} Mark Dechesne ${ }^{4}$

Willem H. van Boom

w.h.van.boom@law.leidenuniv.nl

Kees van den Bos

k.vandenbos@uu.nl

Mark Dechesne

m.dechesne@fgga.leidenuniv.nl

1 Department of Civil Law, Leiden University, Steenschuur 25, 2311 ES Leiden, The Netherlands

2 Department of Business Studies, Leiden University, Steenschuur 25, 2311 ES Leiden, The Netherlands

3 Department of Psychology, School of Law, Utrecht University, Heidelberglaan 1, 3584 CS Utrecht, The Netherlands

4 Faculty of Governance and Global Affairs, Leiden University, Schouwburgstraat 2, 2511 CV The Hague, The Netherlands 